\title{
Stoichiometric Active Site Modification Observed by Alkali Ion Titrations of Sn-Beta
}

Elliot, Samuel Gilbert; Tosi, Irene; Meier, Sebastian; Martinez-Espin, Juan S.; Tolborg, Søren; Taarning, Esben

\section{Published in:}

Catalysis Science \& Technology

Link to article, DOI:

10.1039/C9CY01189G

Publication date:

2019

Document Version

Peer reviewed version

Link back to DTU Orbit

Citation (APA):

Elliot, S. G., Tosi, I., Meier, S., Martinez-Espin, J. S., Tolborg, S., \& Taarning, E. (2019). Stoichiometric Active Site Modification Observed by Alkali lon Titrations of Sn-Beta. Catalysis Science \& Technology, 9(16), 43394346. https://doi.org/10.1039/C9CY01189G

\section{General rights}

Copyright and moral rights for the publications made accessible in the public portal are retained by the authors and/or other copyright owners and it is a condition of accessing publications that users recognise and abide by the legal requirements associated with these rights.

- Users may download and print one copy of any publication from the public portal for the purpose of private study or research.

- You may not further distribute the material or use it for any profit-making activity or commercial gain

- You may freely distribute the URL identifying the publication in the public portal 


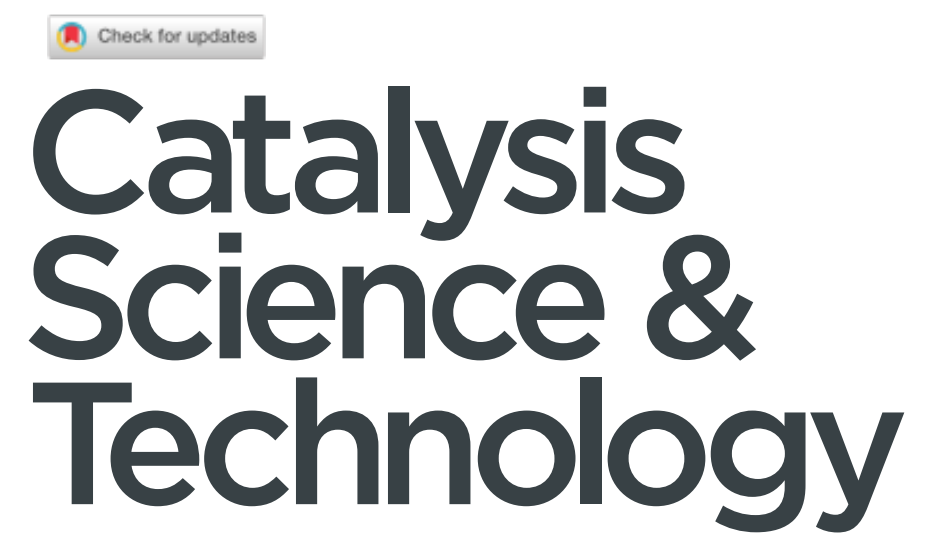

\section{Accepted Manuscript}

This article can be cited before page numbers have been issued, to do this please use: S. G. Elliot, I. Tosi,

S. Meier, J. Martinez espin, S. Tolborg and E. Taarning, Catal. Sci. Technol., 2019, DOI:
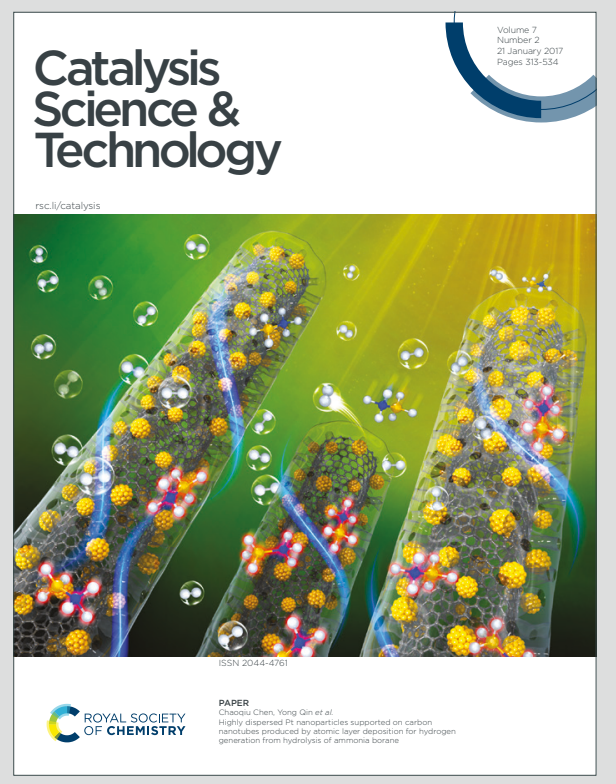

This is an Accepted Manuscript, which has been through the Royal Society of Chemistry peer review process and has been accepted for publication.

Accepted Manuscripts are published online shortly after acceptance, before technical editing, formatting and proof reading. Using this free service, authors can make their results available to the community, in citable form, before we publish the edited article. We will replace this Accepted Manuscript with the edited and formatted Advance Article as soon as it is available.

You can find more information about Accepted Manuscripts in the Information for Authors.

Please note that technical editing may introduce minor changes to the text and/or graphics, which may alter content. The journal's standard Terms \& Conditions and the Ethical guidelines still apply. In no event shall the Royal Society of Chemistry be held responsible for any errors or omissions in this Accepted Manuscript or any consequences arising from the use of any information it contains. 


\section{Journal Name}

\section{ARTICLE}

\section{Stoichiometric Active Site Modification Observed by Alkali Ion Titrations of Sn-Beta}

Received 00th January 20xx, Accepted 00th January 20xx DOI: $10.1039 / \times 0 \times x 00000 x$ www.rsc.org/

\author{
Samuel G. Elliot, ${ }^{* a}$ Irene Tosi, ${ }^{* a}$ Sebastian Meier, ${ }^{a}$ Juan S. Martinez-Espin ${ }^{b}$, Søren Tolborg ${ }^{b}$ and Esben \\ Taarning ${ }^{b}$
}

Sn-Beta zeolite can convert carbohydrate feedstocks through different pathways into a variety of chemical building blocks. Alkali salts influence the selectivity between these pathways, but the details of the alkali ion effect on the catalyst have remained unclear. Here, we combine the systematic variation of tin content in Sn-Beta zeolite with alkali ion titrations and functional assays to assess the stochiometry of alkali binding and the prospect of predicting operation optima from catalyst properties. The approach is used to evaluate the product selectivity of defined catalyst states for the conversion of glucose to methyl lactate formation and to characterise the catalytic behavior of the active site with respect to the degree of titration. The optimum selectivity to methyl lactate was found at similar ratios of alkali and active tin for catalyst of different tin loadings, indicating a stochiometric correlation between added alkali ions and tin content in the Sn-Beta zeolite. The observations also indicate that a double dissociation of the active site occurs and that titration between three states is possible. The proton form of Sn-Beta has a poor methyl lactate selectivity, whereas a single exchange of a proton by potassium at the active site leads to a catalytic form with a very high selectivity, while double exchange leads to a catalytically inactive state of the active site. Exchange phenomena at the active site were corroborated by FT-IR spectroscopy, which showed that potassium interacts with hydroxyl groups in the vicinity of Sn.

\section{Introduction}

The shift from fossil to renewable resources is a transition of increasing urgency. Carbohydrates represent one of the best candidates to function as renewable substrates for future chemical production. Carbohydrate conversion to useful chemicals can be catalysed by heterogeneous zeolite catalysts, which are established catalysts in the petrochemical industry. Among the zeolite catalysts, particular attention for carbohydrate conversion has been devoted to tin-containing zeolites, especially Sn-Beta. ${ }^{1}$

The presence of framework tin sites in a beta zeolite results in a highly Lewis acidic zeolite that is able to catalyse transformations of biomass feedstocks. ${ }^{2}$ Sn-Beta is an extensively studied catalyst for carbohydrate conversions including isomerisation, ${ }^{3}$ epimerisation ${ }^{4,5}$ and conversion to lactates. ${ }^{1,6}$ During the last two decades, a multitude of theoretical and spectroscopic studies have been carried out in order to characterise the active sites of Sn-Beta. ${ }^{7-15}$ Tin incorporated in a BEA zeolite structure has nine unique crystallographic sites, which can be grouped into three sets based on their connectivity. ${ }^{7-9,12,16}$ Use of FT-IR and ${ }^{119}$ Sn-NMR

\footnotetext{
a. Department of Chemistry, Technical University of Denmark, Kemitorvet, 2800Kgs. Lyngby, Denmark

b. Haldor Topsøe A/S, Haldor Topsøes Allé 1, 2800-Kgs. Lyngby, Denmark *Theses authors contributed equally.

Electronic Supplementary Information (ESI) available: [details of any supplementary information available should be included here]. See DOI: 10.1039/x0xx00000x
}

has indicated at least two types of active sites with varying populations and strengths of Lewis acidity..$^{10,11,14,17-21}$ These two sites are commonly referred to as closed and open sites, and differ in the coordinative environment of tin. ${ }^{12,22}$ Closed sites have a tetrahedral coordinated environment where four siloxy groups bind to the tin, while open sites are in a partially hydrolysed environment where one or more of the siloxy groups are substituted by hydroxy groups. The two sites are proposed to have different reactivity. ${ }^{23-25}$

Despite of the strong interest and urgency in producing new chemicals from carbohydrates, structure-activity relations of the active sites in heterogeneous zeolite catalysts remain difficult to establish. Consequently, means of modifying process selectivity to products of choice are only slowly emerging. In the case of Sn-Beta, the effect of the chosen solvent $6,26,27$ or an alkali additive ${ }^{28}$ on product distribution have been described for the conversion of glucose to methyl lactate. In the presence of small amounts of alkali salts, the selectivity to methyl lactate can be increased significantly while reducing by-product formation. ${ }^{28}$ This "alkali effect" has been correlated to initial rate measurements showing that low concentrations of alkali salt increase carbon-carbon bond cleavage, leading to an increase in the rate of methyl lactate formation. ${ }^{29}$ Simultaneously, the presence of these alkali salts reduce both the yield and rate of competing reactions, including Lewis acid catalysed formation of longer alpha-hydroxy esters and Brønsted acid catalysed formation of glycosides or furanic compounds. This alkali effect has been shown to depend on the nature of the counter anion, with basic ions such as carbonate 
leading to stoichiometric ion exchange due to a concurrent acidbase reaction. For such alkali salts, an initial steep activation of the catalyst for methyl lactate formation is followed by a second regime of overall catalyst deactivation at increasing concentrations of alkali salt. ${ }^{28,29}$

In the current study, we investigate the quantitative relationship between tin in Sn-Beta and added alkali salts, for the conversion of glucose to methyl lactate. A systematic investigation of functional effects was conducted through double-titration of the catalysts by varying both the amounts of active site tin and of the alkali ion dopants. Catalysts were characterised by $\mathrm{NH}_{3}$-TPD and FT-IR, where ammonia desorption emerges as a quantitative indicator for activity in the conversion of glucose into methyl lactate by post-treated SnBeta zeolites containing different amount of tin. Moreover, the interaction between alkali and the tin active sites was studied by FT-IR analysis of zeolite samples titrated with different aqueous solutions of potassium carbonate. Differences in acidity and structure at the active site of the various samples were evident from experiments using deuterated acetonitrile as probe molecule. We thus found that single alkali exchange at the tin site converts the catalyst to a form with higher propensity for methyl lactate formation, while a second exchange with alkali ions hinders methyl lactate formation. The results indicate that optimum operation conditions can be predicted from solid-state characterisation of the catalyst, without the need for an empirical optimisation of the active-site modifying additive.

\section{Experimental}

\section{Synthesis of Post-treated Sn-Beta Catalysts}

The catalysts were prepared following the procedure previously described by Hammond et al using target $\mathrm{Si} / \mathrm{Sn}$ ratios of 25, 50, 100, 150, 200 and 400, respectively. ${ }^{30}$ The commercial H-Beta $(100 \mathrm{~g}, \mathrm{Si} / \mathrm{Al}=25$, Zeolyst $)$ was dealuminated by acidic treatment (13 $\mathrm{M} \mathrm{HNO}_{3}, 20 \mathrm{~mL} / \mathrm{g}, 100{ }^{\circ} \mathrm{C}, 20$ hours) and the resulting dealuminated beta zeolite was used as the starting material for the preparation of Sn-Beta. Tin incorporation was performed by incipient wetness with an aqueous solution of $\mathrm{SnCl}_{4} \cdot 5 \mathrm{H}_{2} \mathrm{O}$ (Sigma-Aldrich, 98\%) at the desired concentration. Subsequently, the catalyst samples were dried overnight at 120 ${ }^{\circ} \mathrm{C}$ and calcined at $550{ }^{\circ} \mathrm{C}$ for 6 hours. In all cases, the catalyst preparation closely achieved incorporation of the targeted nominal Si/Sn ratios (Table S1).

In order to investigate the interaction between potassium and tin active sites by FT-IR spectroscopy, $400 \mathrm{mg}$ of Sn-Beta (100) catalyst was stirred at room temperature in $22 \mathrm{~mL}$ of aqueous solutions of potassium carbonate at concentrations of 0.40 or $3.0 \mathrm{mM}$. After 3 hours of stirring, the impregnated zeolites were recovered by filtration and dried overnight at 120 ${ }^{\circ} \mathrm{C}$.

\section{Catalysts Characterisation}

Catalyst characterisation is detailed in the Supporting Information. Briefly, the framework structures of the synthesised catalysts were confirmed by Powder $r_{\text {icl }} X_{- \text {Ray }}$ Diffraction (XRD) using a X'Pert diffractohieter (P/Aillips): Elemental compositions were determined by XRF analysis using a Supermini 200 (Rigaku) and by ICP analysis using an Agilent 720 ICP for trace amounts of $\mathrm{Na}, \mathrm{K}$ and Li. The acidic properties were studied qualitatively and quantitatively by Ammonia Temperature-Programmed Desorption using a Micrometrics AutoChem II 2920 Chemisorption Analyzer. The BET surface area and the pore volume were measured by nitrogen physisorption using an Autosorb automatic surface area and pore analyser from Quantachrome Instruments. FT-IR spectra were acquired on a Vertex 70 spectrometer. Pellets with $1 \mathrm{~cm}$ diameter were prepared using $20 \mathrm{mg}$ of zeolite and were held in a quartz cell connected to a glass circulating vacuum system. The zeolites were pre-treated at room temperature under vacuum overnight and at $450{ }^{\circ} \mathrm{C}$ for one hour. After the acquisition of the blank spectra (at room temperature in the absence of $\mathrm{CD}_{3} \mathrm{CN}$ ), the deuterated acetonitrile was used as probe molecule for studying the acidity of the samples. $\mathrm{CD}_{3} \mathrm{CN}$ was dosed from $1.5 \times 10^{-2}$ mbar to 5 mbar and FT-IR spectra were recorded in situ at different pressures. After the adsorption measurements, the samples were kept under vacuum at room temperature for one hour and the FT-IR spectra of the desorption were recorded. The surface topology of the prepared catalysts was investigated by scanning electron microscopy using a FEI Quanta 200 ESEM FEG instrument (see Supporting Information for additional details on catalyst characterisation).

\section{Reactions}

In a typical experiment, $360 \mathrm{mg}$ D-Glucose (98\%, Sigma-Aldrich), $90 \mathrm{mg}$ Sn-Beta catalyst, $55 \mathrm{mg}$ DMSO (internal standard) and 5 $\mathrm{mL}$ methanol were added to a reaction vial. The mixture was reacted for 4 hours at $160^{\circ} \mathrm{C}$ in a Biotage Initiator (or Initiator+) microwave reactor and the reacted mixture was then filtered through a $0.22 \mu \mathrm{m}$ Nylon syringe filter. $500 \mu \mathrm{L}$ sample and $50 \mu \mathrm{L}$ d4-Methanol were transferred to an NMR tube for analysis. In reactions containing alkali salts, stock solutions of potassium carbonate in methanol were used in place of pure methanol as the solvent, to obtain the desired amount of potassium. A blank reaction with alkali and without Sn-Beta was performed, showing that no detectable base catalysed dehydration takes place by potassium carbonate under the employed reaction conditions (Figure S8).

\section{Nuclear Magnetic Resonance analysis}

Samples were analysed on an $800 \mathrm{MHz}$ Bruker Avance III NMR spectrometer equipped with a $\mathrm{TCl}$ cryoprobe. ${ }^{13} \mathrm{C}-\mathrm{NMR}$ spectra were recorded using inverse-gated decoupling to avoid nuclear Overhauser signal enhancement. Yields were determined by relating product integrals to signal internal of an internal standard of known amount.

Solid state ${ }^{119}$ Sn MAS NMR spectra of Sn-Beta catalysts with ratios $\mathrm{Si} / \mathrm{Sn} 25$ and 50 were acquired as rotor-synchronised Hahn-Echo experiments on a Bruker $600 \mathrm{MHz}$ NMR spectrometer with $15 \mathrm{kHz}$ spinning. Solid state NMR spectra 
used $90^{\circ}$ radio-frequency pulse of $3.75 \mu \mathrm{s}$, inter-scan recycle delay of $30 \mathrm{~s}$, and data acquisition for $31 \mathrm{~ms}$.

\section{Data fitting}

Yields of methyl lactate were fitted to a double dissociation model using equations (2-4) employing OriginPro $2018 \mathrm{~b}$ data fitting software. Further details are provided in the supporting information.

\section{Results and discussion}

Correlation between tin content and optimum concentration of alkali dopant

Catalytically active Sn-Beta materials were all prepared by post synthesis from the same batch of dealuminated Al-Beta. Catalysts were produced to provide nominal $\mathrm{Si} / \mathrm{Sn}$ ratios ranging from 25 to 400, resulting in experimental $\mathrm{Si} / \mathrm{Sn}$ ratios as provided in table S1. The prepared catalyst series was then tested in the conversion of glucose, where the sugar was reacted in methanol containing different concentrations of an alkali salt (here potassium carbonate) and the performance was evaluated based on the formation of methyl lactate at full conversion (Figure 1).

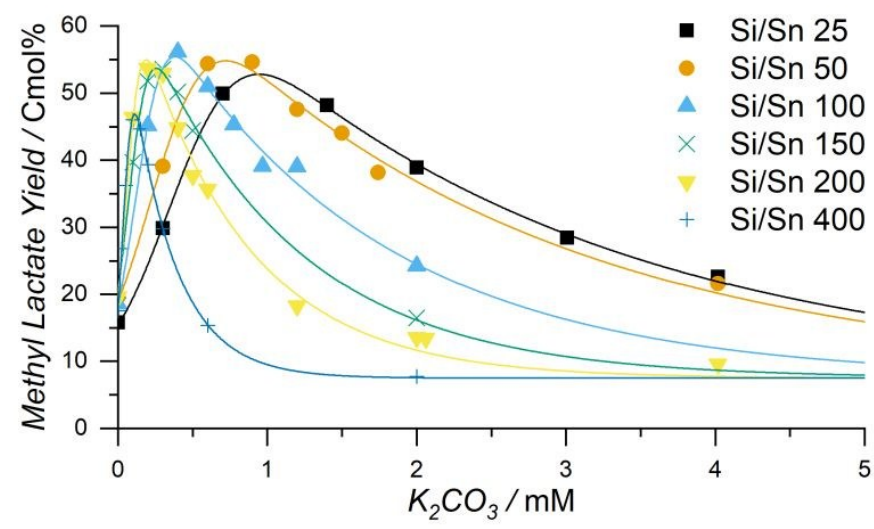

Figure 1 - Methyl lactate yield from glucose at varying concentrations of potassium carbonate using Sn-Beta catalysts with different tin content. The curves are a guide to the eye. Reaction conditions: $360 \mathrm{mg}$ D-Glucose, $90 \mathrm{mg}$ Sn-Beta, 55
$\mathrm{mg}$ DMSO (internal standard) and $5 \mathrm{~mL}$ potassium carbonate in methanol, reacted for 4 hours at $160^{\circ} \mathrm{C}$.

Each catalyst shows a distinct (and different) optimum potassium carbonate concentration for the formation of methyl lactate, consistent with previously described effects for alkali salts of basic anions. ${ }^{28,29}$ Addition of minor amounts of potassium carbonate increases the activity for methyl lactate formation, while over-titration reduces the activity for both methyl lactate and direct dehydration products (Scheme S1 and Figures S4-6). The experiments in Figure 1 show that increasing the tin content of the catalyst results in a shift of the optimum alkali concentration towards higher concentrations. This trend indicates a correlation between the amount of tin and the amount of potassium carbonate that is required to fully activate the catalyst for methyl lactate formation. By normalising these data with respect to tin content (Figure 2, black circles), a linear correlation is found between tin content and the alkali optimum for the prepared Sn-Beta catalysts with nominal Si/Sn, ratios of 50-400, while deviations from the linearity alrélbserveavat high tin content (25).

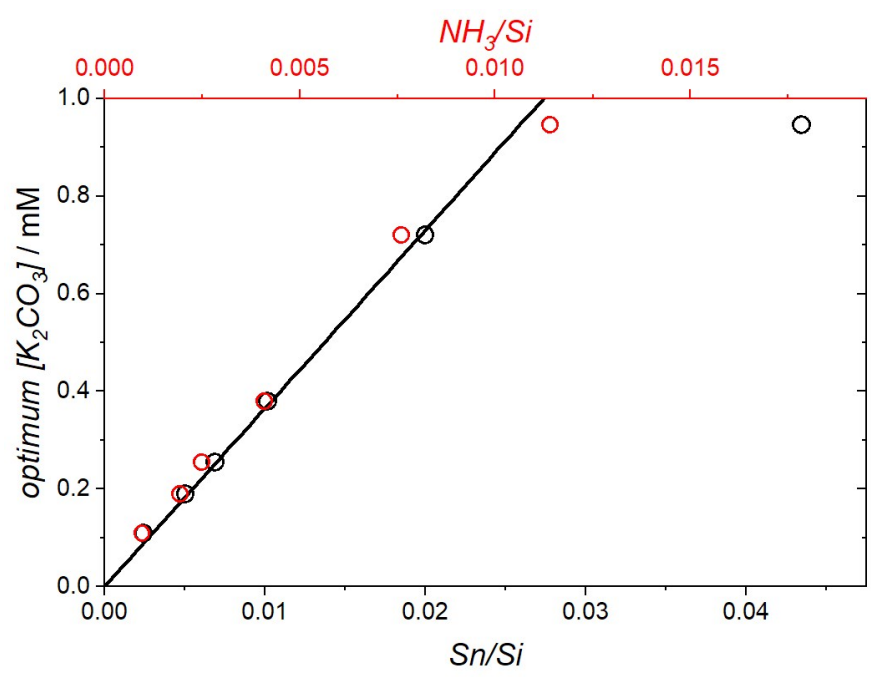

Figure 2 - Optimum potassium carbonate concentration for methyl lactate formation as a function of tin content determined by elemental analysis (black) and tin active sites by ammonia absorption (red), indicating a linear correlation to tin incorporated at the active site and a stoichiometric effect of alkali at the active
site. Reaction conditions: $360 \mathrm{mg}$ D-Glucose, $90 \mathrm{mg}$ Sn-Beta, $55 \mathrm{mg}$ DMSO (internal standard) and $5 \mathrm{~mL}$ potassium carbonate in methanol, reacted for 4 hours at $160^{\circ} \mathrm{C}$.

\section{Quantification of active tin sites by $\mathrm{NH}_{3}$-TPD}

The concentration of catalytically active tin sites was determined by $\mathrm{NH}_{3}$-TPD to normalise the activity by the active species. The ammonia desorption per tin (Figure 3 ) showed only small variations in desorption for the catalysts containing 50$400 \mathrm{Si} / \mathrm{Sn}$. Meanwhile, the Si/Sn 25 catalyst exhibited 30\% lower ammonia absorption/desorption, indicating a change in the nature of the incorporated tin at higher loadings.

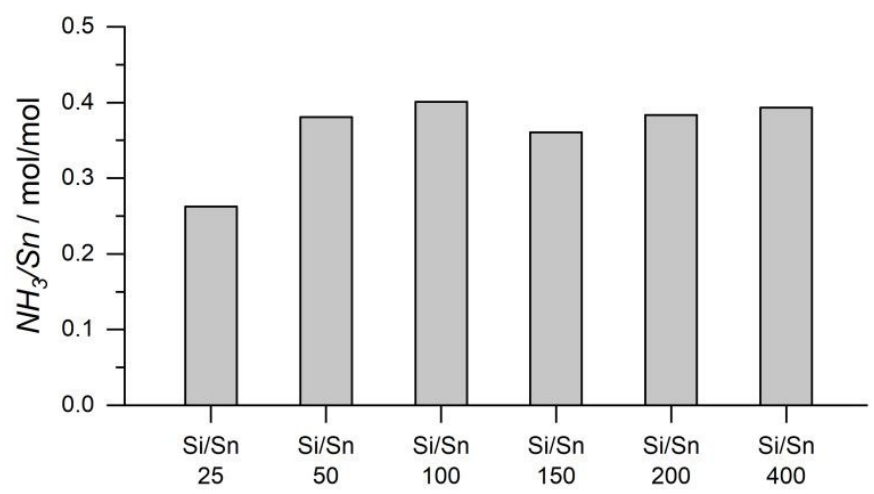

Figure 3 - Ammonia desorption per tin $(\mathrm{mol} / \mathrm{mol})$ of $\mathrm{Sn}$-Beta catalysts with tin loadings from 25 to $400 \mathrm{Si} / \mathrm{Sn}$. Values were determined by integration of the $\mathrm{NH}_{3}$ TPD absorption/desorption peak at $255^{\circ} \mathrm{C}$.

The expected cause is the formation of catalytically inactive extra-framework $\mathrm{SnO}_{2}$, for which the formation at high tin loadings is well known and was confirmed by XRD (Figure S2) and by solid state ${ }^{119} \mathrm{Sn}$ MAS NMR (Figure 4). ${ }^{31,32}$ Here, significant amounts of $\mathrm{SnO}_{2}$ (with an intense signal near -600 ppm) was observed in addition to hydrated framework sites yielding a broad signal near $-700 \mathrm{ppm}$. In contrast, only a small signal for extra-framework $\mathrm{SnO}_{2}$ is observed for the $\mathrm{Si} / \mathrm{Sn} 50$ 
catalyst, consistent with the higher fraction of catalytically active $\mathrm{Sn}$ as found by $\mathrm{NH}_{3}$-TPD. The heterogeneity of the framework sites is witnessed by their broad ${ }^{119} \mathrm{Sn}$ MAS NMR signal and by an additional broad peak between -600 and -650 $\mathrm{ppm}$. These data corroborate the presence of multiple tin species, of which only around $35-40 \%$ are catalytically active (titratable), while the rest may be minor tin oxide species or other forms of spectator tin.

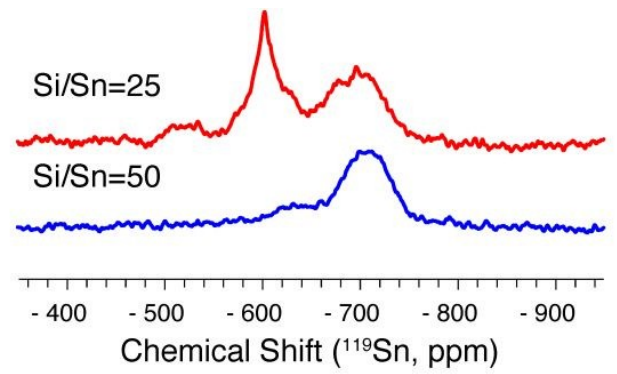

Figure 4- ${ }^{119}$ Sn MAS NMR spectra for Sn-Beta catalysts with tin loadings of 25 and $50 \mathrm{Si} / \mathrm{Sn}$.

A comparison of the $\mathrm{Si} / \mathrm{NH}_{3}$ ratios to the alkali optimum (Figure 2 , red), thus removing contributions from inactive tin, shows a close linear correlation for all catalysts including the Si/Sn 25 catalyst, validating the obtained $\mathrm{NH}_{3}$-TPD results.

\section{Identical optima for catalysts with varying Si/Sn ratios upon normalisation to active site tin}

Ammonia desorption was employed as an indicator for catalytically active tin sites and was subsequently used to normalise the data from Figure 1 to the amount of tin (Figure 5). This correlation makes titrations of catalysts with different tin content comparable and shows consistent behaviour of tin active sites in these catalysts, as displayed by the linear correlation of alkali optima (Figure 2). All catalysts show trends with an optimum between $\mathrm{K} / \mathrm{NH}_{3}=0.50$ and $0.85 \mathrm{~mol} / \mathrm{mol}$. Importantly, the observed consistency indicates that optimum operation conditions can be predicted in the Si/Sn 25-400 range through catalyst characterisation by $\mathrm{NH}_{3}$-TPD, without the need for empirical optimisation of operating conditions.

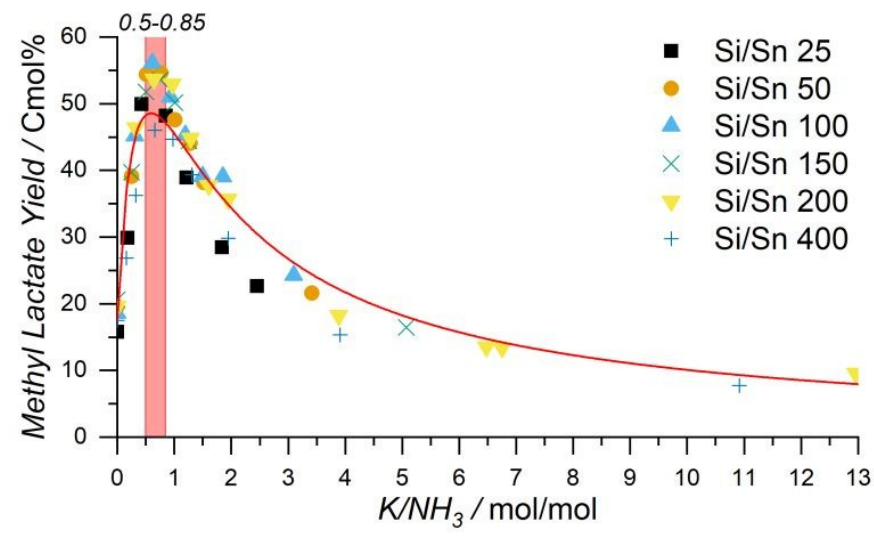

Figure 5 - Effect of addition of potassium carbonate on methyl lactate yield, in the catalytic conversion of glucose by Sn-Beta containing different amounts of Sn. The yields are displayed in dependence on the $\mathrm{K}^{-} \mathrm{NH}_{3}$ ratio determined by $\mathrm{NH}_{3}$-TPD, dissociation model fitted to the combined data from all the catalysts.
Comparison of functional data to a two-step titration,modelle Online Observation of product selectivity suggest that the catalyst titrates between three regimes upon alkali addition. The first regime has a high propensity for dehydration and a lower propensity for C-C bond cleavage (see supplementary Figure S7). The second regime favours retro-aldol cleavage observable by high methyl lactate formation (Figure 5) and the final regime shows low propensity for retro-aldol cleavage and especially dehydration.

The alkali ion titration of two sites of different acidity was modelled by fitting all data points (normalised to the number of Sn-active sites using the $\mathrm{NH}_{3}$-TPD data) to a $\left[\mathrm{K}^{+}\right]$-dependent double dissociation model (red line in Figure 5). The fit indicates that the observed titration curve of the active site, as observed from functional data through methyl lactate formation, is consistent with a titration of two sites (Equation 1).

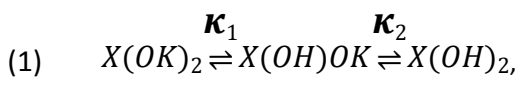

where $\mathrm{X}(\mathrm{OH})_{2}, \mathrm{X}(\mathrm{OH}) \mathrm{OK}$ and $\mathrm{X}(\mathrm{OK})_{2}$ are the protonated, single alkali exchanged and double alkali exchanged active site, respectively, while $\boldsymbol{\kappa}_{1}$ and $\boldsymbol{\kappa}_{2}$ are dissociation constants (normalised to $\mathrm{NH}_{3}$ ). The model of [ $\left.\mathrm{K}^{+}\right]$-dependent dissociation is analogous to a model of stepwise, $\left[\mathrm{H}^{+}\right]$-dependent dissociation for diprotic acids. In this simple model, fractions $f$ of the different active site forms were computed as a function of alkali concentration by Equations 2-4 as

$$
\begin{array}{ll}
\text { (2) } f_{X(\mathrm{OH})_{2}}=\frac{\boldsymbol{\kappa}_{1} \boldsymbol{\kappa}_{2}}{\left[K^{+}\right]^{2}+\left[K^{+}\right] \boldsymbol{\kappa}_{1}+\boldsymbol{\kappa}_{1} \boldsymbol{\kappa}_{2}} \\
\text { (3) } f_{X(\mathrm{OH}) O K}=\frac{\left[K^{+}\right] \boldsymbol{\kappa}_{1}}{\left[K^{+}\right]^{2}+\left[K^{+}\right] \boldsymbol{\kappa}_{1}+\boldsymbol{\kappa}_{1} \boldsymbol{\kappa}_{2}} \\
\text { (4) } f_{X(\mathrm{OK})_{2}}=\frac{\left[K^{+}\right]^{2}}{\left[K^{+}\right]^{2}+\left[K^{+}\right] \boldsymbol{\kappa}_{1}+\boldsymbol{\kappa}_{1} \boldsymbol{\kappa}_{2}}
\end{array}
$$

Experimental yields of methyl lactate (Figure 5) and the major dehydration product methyl trans-2,5,6-trihydroxy-3hexenoate ${ }^{33}$ (THM, Figure S7) were fitted as linear combinations of the three sites, contributing to the observed yield according to their selectivity $S$ for the respective product:

$$
\begin{gathered}
\text { (5) Yield }=f_{(\mathrm{OH})_{2}} \cdot S_{(\mathrm{OH})_{2} \text { site }}+f_{(\mathrm{OH})(\mathrm{OK})} \cdot S_{(\mathrm{OH})(\mathrm{OK}) \text { site }} \\
+\quad f_{(\mathrm{OK})_{2}} \cdot S_{(\mathrm{OK})_{2} \text { site }}
\end{gathered}
$$

The residual error in the fit of Figure 5 can be explained by the simplicity of the stepwise dissociation model given by Equation 1 , which was chosen to minimise the number of free parameters and avoid overfitting. This model does not account for the presence of possible in-homogeneities in active site structures and alkali exchange positions. The model predicts that the dissociation constant of the first site is approximately 2.5-fold higher (1.21 when normalised to $\mathrm{NH}_{3}$ ) than the dissociation constant of the second site ( 0.53 when normalised to $\mathrm{NH}_{3}$ ). The difference in dissociation constants is relatively small and therefore the second dissociation is expected to initiate before the first site is completely dissociated, which is 
evidenced by the observed optimum K/Sn ratio of less than 1 The methyl lactate yields from protonated and double alkali exchanged active sites are predicted to be $18 \%$ and close to $0 \%$, respectively. These values correspond to the selectivity without added alkali and the selectivity that is approached at very high alkali concentrations, respectively (Figure 5). According to the fit in Figure 5, the single exchanged site has high selectivity for methyl lactate formation with theoretical yields of the isolated site approaching $100 \%$ selectivity for the formation of methyl lactate. These findings are consistent with the previous observation of selectivity above $75 \%$ for optimised conditions and catalysts, $^{28}$ and closely correlates with the linear extrapolation of the data from the initial exchange phase $(<0.5$ $\mathrm{K} / \mathrm{NH}_{3}$ ) which predicts $88 \% \pm 5 \%$ selectivity at a $\mathrm{K} / \mathrm{NH}_{3}$ of 1 . The fit of THM yields (Figure S7) employing dissociation constants obtained from the alkali-dependence of methyl lactate yields were in excellent agreement with experimental data. Hence, identical titration behaviour of the active site leads to increasing methyl lactate yields and decreasing THM yields. The protonated active site has mediocre selectivity for THM (14\% yield), which is abolished upon single ( $3 \%$ yield) and double exchange ( $0 \%$ yield) with potassium (Figure S7).

\section{IR probing of alkali binding to Sn-Beta}

The linear dependence of the alkali optimum on active site tin content and the identical profiles of yields upon normalising alkali concentrations to active site tin indicate a direct and linear/stoichiometric effect of potassium carbonate on the Snactive site. To substantiate this stoichiometric effect of potassium ions on tin active sites, acidic properties of the catalyst in the presence and the absence of alkali were characterised using FT-IR and $\mathrm{CD}_{3} \mathrm{CN}$ as probe molecule. SnBeta (100) catalyst was characterised at three different stages of its activity curve: in the absence of alkali, at near optimal potassium carbonate concentration as well as at excess alkali salt concentration ( $\mathrm{K} / \mathrm{NH}_{3}$ at $0,0.59$ and 4.43 , respectively). Despite of the low amount of potassium compared to the zeolite, the resulting FT-IR spectra of the potassium-exchanged materials show different intensity of the stretching of the silanols in the $\mathrm{O}-\mathrm{H}$ region (Figure 6 ). Increasing concentrations of potassium carbonate lead to a decrease of the sharp signal at $3735 \mathrm{~cm}^{-1}(\mathrm{O}-\mathrm{H} \text { stretch of terminal silanols })^{34}$ and the overall broad O-H band at $3696 \mathrm{~cm}^{-1}$ (O-H stretch of hydrogen-bonded silanols with weak Brønsted acidic character), ${ }^{34}$ which disappears at high concentration of potassium. The $\mathrm{O}-\mathrm{H}$ stretching of stannanol groups is ascribed to a band at $3664 \mathrm{~cm}$ ${ }^{1} .^{34}$ This band is difficult to resolve on dealuminated samples, due to overlap with broad silanol stretching bands. These findings are consistent with the hypothesis that alkali interaction occurs through ion exchange with $\mathrm{OH}$ protons ${ }^{35}$ even in the presence of weakly basic counter ions.

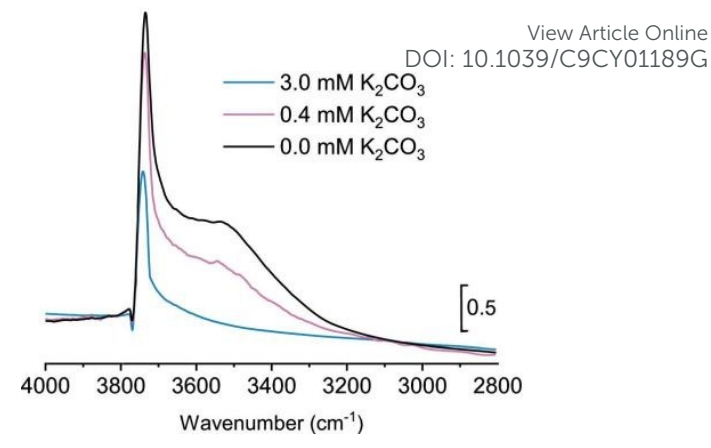

Figure 6 - The $\mathrm{OH}$ stretching region of the FT-IR spectra of post-treated Sn-Beta zeolite (100) without alkali (black) and after impregnation in $0.4 \mathrm{mM}$ (pink) and 3 $\mathrm{mM}$ (blue) aqueous potassium carbonate solution, corresponding to the optimum concentration for the production of methyl lactate and a 7.5-fold excess. FT-1R spectra were com
and $1988 \mathrm{~cm}^{-1}$.

Subsequently, $\mathrm{CD}_{3} \mathrm{CN}$ was used to probe Lewis acid tin sites of $\mathrm{Sn}$-Beta. After adsorption of $\mathrm{CD}_{3} \mathrm{CN}$ probe molecules onto the zeolite, the characteristic bands between 2200 and $2350 \mathrm{~cm}^{-1}$ could be observed (Figure 7, $\mathrm{C} \equiv \mathrm{N}$ stretching associated to adsorbed acetonitrile on acid sites). The peak at $2310 \mathrm{~cm}^{-1}$, corresponding to $\mathrm{CD}_{3} \mathrm{CN}$ adsorbed to the tin site, is the signal first appearing at low pressure, as this is the strongest coordinative site. However, the post-synthetic material does not have the structural homogeneity needed for resolving $\mathrm{CD}_{3} \mathrm{CN}$ adsorption to open and closed sites, i.e. sites where three or four siloxy groups of the catalyst framework bind to tin. Therefore, it was not possible to distinguish between the two configurations in post-synthetic material by the signals reported in the literature at 2316 and $2308 \mathrm{~cm}^{-1}$ for hydrothermal SnBeta zeolites. ${ }^{12,19,22,36}$

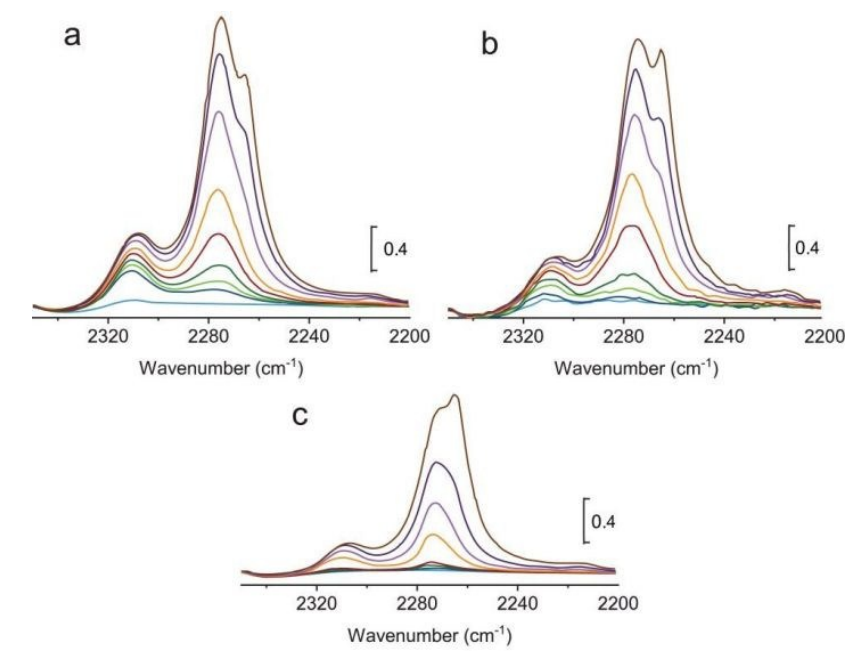

Figure 7 - In-situ FT-IR measurements of $\mathrm{CD}_{3} \mathrm{CN}$ adsorption on Sn-Beta zeolites increasing the pressure from $1.5 \times 10^{-2}$ mbar to 5 mbar. Clockwise from the top left: post-treated Sn-Beta without impregnation (a), after treatment in $0.4 \mathrm{mM}$ (b) and after treatment in $3 \mathrm{mM}$ (c) aqueous solution of potassium carbonate. FT-IR spectra were compared after normalisation to the framework bands at $1875 \mathrm{~cm}^{-1}$

The presence of potassium in the material resulted in a change in the relative intensity of the peaks at $2310 \mathrm{~cm}^{-1}\left(\mathrm{CD}_{3} \mathrm{CN}\right.$ adsorbed on tin) and at $2275 \mathrm{~cm}^{-1}\left(\mathrm{CD}_{3} \mathrm{CN}\right.$ adsorbed on silanol groups). The band at $2265 \mathrm{~cm}^{-1}$ corresponds to physisorbed $\mathrm{CD}_{3} \mathrm{CN}$. $^{34,37}$ The band corresponding to the adsorption on tin becomes less intense after treatment of the catalyst with 
increasing concentrations of potassium carbonate. These changes indicate that potassium interacts with hydroxyl groups in the vicinity of tin ( $\mathrm{Si}-\mathrm{OH}$ and possibly $\mathrm{Sn}-\mathrm{OH}$ ) causing tin to become (partially) hindered in binding $\mathrm{CD}_{3} \mathrm{CN}$. This finding is consistent with $\mathrm{CD}_{3} \mathrm{CN}$ desorption data at room temperature, see Figure 8. After desorption under vacuum, the sample without potassium shows a higher amount of probe molecule adsorbed on both tin and $\mathrm{OH}$ sites, indicating higher accessibility compared to the alkali treated samples. Overall, these results indicate that potassium ions bind at silanol groups in the vicinity of the tin active sites. Interactions with stannanols are plausible but not determinable due to low intensity and signal overlap in IR. The presence of alkali also hinders the interaction of $\mathrm{CD}_{3} \mathrm{CN}$ with tin sites. This finding reflects the titration effect of the active sites that substantially changed the catalytic function of Sn-Beta.
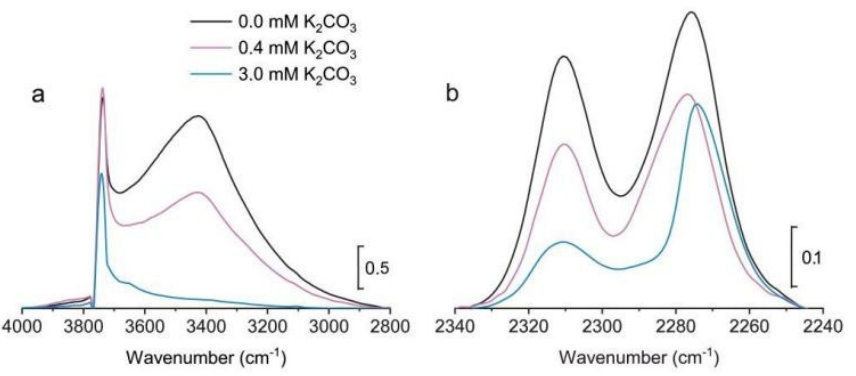

Figure 8 - Desorption of $\mathrm{CD}_{3} \mathrm{CN}$ at room temperature for one hour under vacuum FT-IR spectra of Sn-Beta zeolites with and without alkali are shown. (a) $\mathrm{OH}$ region of the spectra and (b) FT-IR signals of $\mathrm{CD}_{3} \mathrm{CN}$ bands in the same sample. Higher absence of alkali. FT-IR spectra were compared after normalisation to the framework bands at $1875 \mathrm{~cm}^{-1}$ and $1988 \mathrm{~cm}^{-1}$.

\section{The catalyst titrates between three different states}

Structural and activity data on alkali-exchange near the Sn-Beta active site can be combined to yield a plausible model for the structure-activity relationship as follows. As demonstrated, product selectivity trends follow a model for double dissociation indicating that the catalyst can titrate between three different states. Based on previous results, it is unlikely that closed active sites are present in Sn-Beta in polar protic medium. ${ }^{18}$ Rather, the unmodified catalyst is proposed to be present in an octahedral open form (also coordinating two water molecules). In addition, our IR data indicates a modification of both $\mathrm{OH}$ sites and tin sites upon addition of alkali salts. Similarly, loss of hydroxyl protons by solvent alkylation have been observed to result in loss of catalytic activity. ${ }^{38}$ On this basis, a plausible structural model of titration between three tin sites is depicted in Scheme 1, where the protonated form (A) yields various dehydration products with mediocre selectivity, and the double exchanged form is not active for the reactions monitored under the given conditions (C).
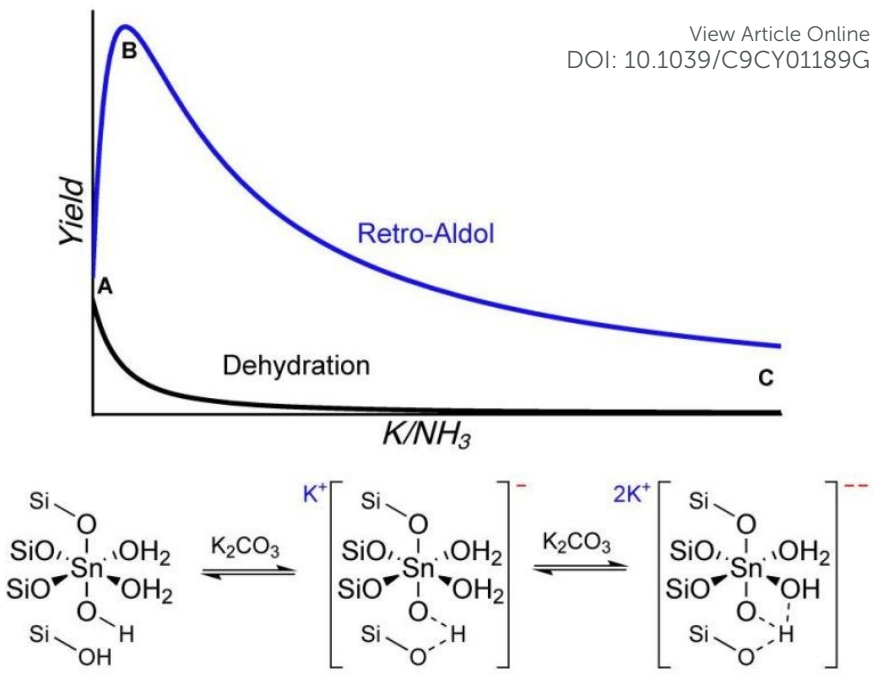

A

B

C

Scheme $\mathbf{1}$ - Identical titration behaviour of the active site lead to an optimum of yields for retro-aldol products and to decreasing THM yields (top). A plausible
model for stoichiometric alkali exchange at the active side is shown on the bottom

The mono-exchanged form (B) is highly selective for retro-aldol cleavage and hence methyl lactate formation, but the exact position of the alkali ion remains more elusive to depict in this form. Our results indicate a reduction in both stannanol and silanol groups, while previous studies using NMR crosspolarisation indicate that a proton is present in the vicinity of the tin site, ${ }^{35}$ even in dehydrated catalyst samples. The atomic location of the alkali ion in this system remains undetermined, but different models may be reconciled when assuming that the protons at the active site are partially coordinated at different sites and possibly in dynamic exchange in a hydrogen bonded network. We believe that a theoretical investigation could shed more light on the coordinative aspect of the ion exchange, and provide further explanations related to its catalytic properties. A tentative representation of the B site is presented with a hydrogen partially coordinated to stannanol and silanol, with a delocalised negative charge. Such a representation is consistent with computational studies by Christanson et al indicating electrostatic stabilisation of reaction intermediates by alkali ions. ${ }^{39}$

\section{Conclusions}

Systematic variations of tin content and potassium dopant concentrations were employed to gain insight into molecular details of active site function in Sn-Beta catalysed carbohydrate conversion to methyl lactate. Titration curves of the active site in Sn-Beta were indirectly obtained through functional data on methyl lactate formation. The functional data are consistent with a stoichiometric binding of alkali at tin active sites, as the optimum alkali concentration increases linearly with the tin content. The optimum potassium concentration is comparable to the concentration of active sites, albeit deactivation by a second binding step yields an optimum potassium to active site ratio below 1 (0.5-0.85). Functional data for catalysts with varying tin content are consistent with the subsequent titration 
of two sites near the tin active site by alkali, where both sites differ in their dissociation constants approximately by a factor three. Such titration between states with different activity is reminiscent of the response of some enzyme active sites to $\mathrm{pH}$ or metal-ion titrations. The protonated active site in Sn-Beta slightly favours dehydration over retro-aldol cleavage in carbohydrate conversion, while single alkali exchange induces high selectivity for retro-aldol cleavage. Double alkali exchange results in reduced selectivity to both pathways. The functional data for titration with potassium carbonate indicate that optimum operation conditions of Sn-Beta can be predicted from catalyst characterisation and do not require empirical optimisation. From these findings, we predict that a catalytic system comprising Sn-Beta and an ion exchange agent capable of only mono exchange will display a very high selectivity in the conversion of glucose to methyl lactate.

\section{Conflicts of interest}

There are no conflicts to declare.

\section{Acknowledgements}

This work was funded by the Innovation Fund Denmark (case number 5150-00023B). NMR spectra were recorded on the spectrometers of the NMR center DTU supported by the Villum foundation. Solid state NMR spectra were acquired on a 600 $\mathrm{MHz}$ spectrometer by Dr. Kasper Enemark Rasmussen, who is gratefully acknowledged for this work.

\section{References}

1 M. S. Holm, S. Saravanamurugan and E. Taarning, ACS Catal., 2010, 328, 602.

2 M. Moliner, Dalton Transactions, 2014, 43, 4197-4208.

3 M. Moliner, Y. Román-Leshkov and M. E. Davis, Proc. Nat. Acad. Sci., 2010, 107, 6164-6168.

4 W. R. Gunther, Y. Wang, Y. Ji, V. K. Michaelis, S. T. Hunt, R. G. Griffin and Y. Román-Leshkov, Nat. Comm., 2012, 3, 1109.

5 S. Li, T. Josephson, D. G. Vlachos and S. Caratzoulas, J. Catal., 2017, 355, 11-16.

6 M. S. Holm, Y. J. Pagán-Torres, S. Saravanamurugan, A. Riisager, J. A. Dumesic and E. Taarning, Green Chem., 2012, 14, 702-706.

7 G. Valerio, A. Goursot, R. Vetrivel, O. Malkina, V. Malkin and D. R. Salahub, J. Am. Chem. Soc., 1998, 120, 11426-11431.

8 S. Shetty, S. Pal, D. G. Kanhere and A. Goursot, Chem. Eur. J., 2005, 12, 518-523.

9 B. D. Montejo-Valencia and M. C. Curet-Arana, J. Phys. Chem. C, 2015, 119, 4148-4157.

10 A. V. Yakimov, Y. G. Kolyagin, S. Tolborg, P. N. R. Vennestrøm and I. I. Ivanova, J. Phys. Chem. C, 2016, 120, 28083-28092.

11 Y. G. Kolyagin, A. V. Yakimov, S. Tolborg, P. N. R. Vennestrøm and I. I. Ivanova, J. Phys. Chem. Lett., 2016, 7, 1249-1253.

12 M. Boronat, P. Concepción, A. Corma, M. Renz and S. Valencia, J. Catal., 2005, 234, 111-118.
13 W. R. Gunther, V. K. Michaelis, M. A. Caporini, R. G. Griffin and Y. Román-Leshkov, J. Am. Chem. Soc., 2014, 136, 6219y62182G

14 P. Wolf, M. Valla, A. J. Rossini, A. Comas-Vives, F. Núñez-Zarur, B. Malaman, A. Lesage, L. Emsley, C. Copéret and I. Hermans, Angew. Chem., 2014, 126, 10343-10347.

15 S.-J. Hwang, R. Gounder, Y. Bhawe, M. Orazov, R. BermejoDeval and M. E. Davis, Top. Catal., 2015, 58, 435-440.

16 P. Wolf, M. Valla, F. Núñez-Zarur, A. Comas-Vives, A. J. Rossini, C. Firth, H. Kallas, A. Lesage, L. Emsley, C. Copéret and I. Hermans, ACS Catal., 2016, 6, 4047-4063.

17 Y. G. Kolyagin, A. V. Yakimov, S. Tolborg, P. N. R. Vennestrøm and I. I. Ivanova, J. Phys. Chem. Lett., 2018, 9, 3738-3743.

18 T. D. Courtney, C.-C. Chang, R. J. Gorte, R. F. Lobo, W. Fan and V. Nikolakis, Microporous Mesoporous Mater., 2015, 210, 6976.

19 J. W. Harris, M. J. Cordon, J. R. Di lorio, J. C. Vega-Vila, F. H. Ribeiro and R. Gounder, J. Catal., 2016, 335, 141-154.

20 S. Roy, K. Bakhmutsky, E. Mahmoud, R. F. Lobo and R. J. Gorte, ACS Catal., 2013, 3, 573-580.

21 V. L. Sushkevich, I. I. Ivanova and A. V. Yakimov, J. Phys. Chem. C, 2017, 121, 11437-11447.

22 M. Boronat, P. Concepción, A. Corma, M. T. Navarro, M. Renz and S. Valencia, Phys. Chem. Chem. Phys., 2009, 11, 28762884.

23 S. K. Brand, J. A. Labinger and M. E. Davis, ChemCatChem, 2016, 8, 121-124.

24 G. Li, E. A. Pidko and E. J. M. Hensen, Catal. Sci. Tech., 2014, 4, 2241-2250.

25 N. Rai, S. Caratzoulas and D. G. Vlachos, ACS Catal., 2013, 3, 2294-2298.

26 M. Dusselier, P. Van Wouwe, S. De Smet, R. De Clercq, L. Verbelen, P. Van Puyvelde, F. E. Du Prez and B. F. Sels, ACS Catal., 2013, 3, 1786-1800.

27 S. G. Elliot, S. Tolborg, I. Sádaba, E. Taarning and S. Meier, ChemSusChem, 2017, 10, 2990-2996.

28 S. Tolborg, I. Sádaba, C. M. Osmundsen, P. Fristrup, M. S. Holm and E. Taarning, ChemSusChem, 2015, 8, 613-617.

29 S. G. Elliot, S. Tolborg, R. Madsen, E. Taarning and S. Meier, ChemSusChem, 2018, 11, 1198-1203.

30 C. Hammond, S. Conrad and I. Hermans, Angew. Chem. Int. Ed., 2012, 51, 11736-11739.

$31 \mathrm{M}$. Renz, T. Blasco, A. Corma, V. Fornés, R. Jensen and L. Nemeth, Chem. Eur. J., 2002, 8, 4708-4717.

32 L. Botti, R. Navar, S. Tolborg, J. S. Martinez-Espin, D. Padovan, E. Taarning and C. Hammond, Top. Catal., 2018, in press DOI: 10.1007/s11244-018-1078-z.

33 S. Tolborg, S. Meier, I. Sádaba, S. G. Elliot, S. K. Kristensen, S. Saravanamurugan, A. Riisager, P. Fristrup, T. Skrydstrup and E. Taarning, Green Chem., 2016, 18, 3360-3369.

34 R. Otomo, R. Kosugi, Y. Kamiya, T. Tatsumi and T. Yokoi, Catal. Sci. Tech., 2016, 6, 2787-2795.

35 R. Bermejo-Deval, M. Orazov, R. Gounder, S.-J. Hwang and M. E. Davis, ACS Catal., 2014, 4, 2288-2297.

36 C.-C. Chang, H. J. Cho, Z. Wang, X. Wang and W. Fan, Green Chem., 2015, 17, 2943-2951.

37 P. Wu, T. Komatsu and T. Yashima, J. Phys. Chem., 1995, 99, 10923-10931.

38 D. Padovan, L. Botti and C. Hammond, ACS Catal., 2018, 8, 7131-7140.

39 J. R. Christianson, S. Caratzoulas and D. G. Vlachos, ACS Catal., 2015, 5, 5256-5263. 